\title{
Tres perspectivas críticas o para pensar alternativas en el contexto del capitalismo neoliberal
}

\author{
Delia Albarracín \\ Universidad Nacional de Cuyo
}

Resumen: En el contexto actual de profundización de la lógica del capitalismo, este trabajo realiza una revisión de tres perspectivas de pensamiento crítico con el propósito de reflexionar sobre alternativas a los procesos de creciente desigualdad y exclusión. En primer lugar, se recupera el diagnóstico de la situación en el contexto de la Segunda Guerra Mundial realizado por pensadores de la Escuela de Frankfurt. Seguidamente, se exponen los aportes de Franz Hinkelammert sobre su concepción de sujeto y la crítica a la ley del mercado, para finalmente recuperar los estudios del común como acción política frente a los procesos actuales de acumulación a través de la configuración de comunes para su expropiación. Se concluye integrando los aportes de las tres perspectivas como experiencia histórica valiosa para la construcción de alternativas a un sistema que, no obstante su impetuosidad, muestra signos de debilitamiento.

Palabras claves: Dialéctica, sociedad, sujetos, comunes, acción común.

Abstract: In the current context of the deepening of the logic of Capitalism, this work makes a review of three perspectives of critical thinking in order to reflect on alternatives to the processes of growing inequality and exclusion. In the first place, the diagnosis of the situation in the context of World War II made by thinkers of the Frankfurt School is recovered. Following are Franz Hinkelammert's contributions on his conception of the subject and his critique of the law of the market; to finally recover the studies of the common as political action against the current accumulation processes through the configuration of commons for their expropriation. It concludes by integrating contributions from the three perspectives as a valuable historical experience for the construction of alternatives to a system that, despite its impetuosity, shows signs of weakening. 


\section{Introducción}

El presente artículo surge del propósito de abordar la pregunta: ¿A qué tiene que dar respuesta una sociedad alternativa hoy?, que fuera planteada como eje del VI Encuentro del Grupo de Pensamiento Crítico llevado a cabo en la UNA, Costa Rica, a mediados de 2019 . Desde nuestra práctica docente en profesorados universitarios de educación, en cátedras referidas a problemáticas filosóficas, la aclaración de significados de términos y de los lugares desde los cuales se formulan las categorías teóricas es clave para el desarrollo del pensamiento crítico en un contexto de apertura de las ciencias sociales y de proliferación de discursos que expresan distintas formas de apropiación de los principios que legitiman la sociedad moderna. Expresiones como "formar sujetos de democracia", "educar en una ética pública" y en los "derechos humanos" y metas vinculadas a la superación de la crisis económica educativa y el desigual acceso a la educación forman parte del encuadre conceptual de cualquiera de los programas del Banco Mundial y el Banco Interamericano de Desarrollo. El financiamiento para encarar transformaciones en la administración de políticas públicas es prácticamente una política de estado en países como la Argentina, mientras que no sólo no se han alcanzado las metas pregonadas, sino que la crisis económica y la desigualdad constituyen la situación normal a administrar por parte de estados que se van ajustando a los requerimientos del mercado. En este escenario nuestra actividad de docencia se apoya y retroalimenta en una línea de investigación que venimos desarrollando desde hace más de dos décadas sobre filosofía, ética, política y educación.

La incorporación de nuevos aportes sobre el problema de la modernidad en aras de una mayor comprensión del presente requiere siempre un trabajo de correlación con obras precedentes que lograron expresar conceptualmente las profundas contradicciones del orden social moderno. Distintas líneas de indagación analizan las consecuencias destructivas del capitalismo tardío, dialogan con lo ya pensado y pulsan herramientas teórico-prácticas para la construcción de alternativas. En el presente trabajo consideramos tres líneas de análisis cuya aproximación brinda aportes para pensar alternativas a la situación actual. La exposición forma parte del marco teórico específico de un proyecto de investigación en curso pero a la vez intenta reflejar su integración con la línea histórico-crítica en que venimos trabajando. 
Estructuramos el escrito en tres apartados. En el primero exponemos el debate sobre los términos sociedad e individuo que dio la Escuela de Frankfurt en el contexto de finalización de la II Guerra Mundial. Nos interesa poner de relieve su crítica a la modernidad, en tanto proyecto de la clase burguesa disimulado tras un modelo de individuo abstracto de derechos y, a la vez, la reivindicación que esta teoría realiza de su contenido emancipatorio, eclipsado por la racionalidad instrumental. En el segundo apartado, realizamos una exposición del concepto de sujeto desarrollado por Franz Hinkelammert a partir de su estudio de la obra de Marx, el cual lo lleva a una comprensión más profunda de los modos en que el ser humano ha sido oprimido por utopías que algunos sujetos han puesto por encima de la dignidad y la realización humana. En el tercer apartado nos referimos a los estudios del común, recuperando aquellas perspectivas que interpretan lo común como acción política de resguardo de bienes naturales o artificiales que en forma constante pretenden ser apropiados por el neoliberalismo. Cerramos con unas reflexiones finales que ensayan una respuesta a la pregunta que motivó la escritura del presente artículo.

1.Significado de sociedad, individuo y estado en la dialéctica frankfurtiana

La aclaración de los significados de los términos y de los lugares del discurso, así como de las concepciones de hombre y naturaleza subyacentes fue y es siempre un campo de lucha política. Así lo entendió la teoría crítica frankfurtiana a mediados del siglo pasado al ocuparse de un objeto constitutivamente contradictorio: "la sociedad" y del "individuo" en tanto modelo de ser humano portador de las tensiones y contradicciones de la sociedad moderna. Al mismo tiempo, en la medida que esta escuela impugnó los supuestos metafísicos del término "sujeto" presentes en la filosofía europea, no trabajó en dirección de dar otros sentidos al término "sujeto", como sucede en varias corrientes críticas latinoamericanas (Roig y Hinkelammert, entre otras), sino en mostrar la inversión de los principios de una posible emancipación. Veamos este análisis con más detalle.

\subsection{El concepto de sociedad en disputa y las contradic- ciones del individuo como modelo moderno de hombre}

En la obra publicada en 1966, La sociedad. Lecciones de sociología, Horkheimer y Adorno abordan el concepto "sociedad". Lo hacen en un nivel de generalidad que les permite analizar el devenir histórico de la vida humana. Entienden el contenido de la sociedad como el proceso vital de 
la humanidad y van mostrando cómo las relaciones sociales desiguales dan lugar a la estabilización de las formas de organización instituidas por los sectores sociales con mayor poder de decisión. Así muestran cómo el contenido material de la sociedad ya en la filosofía política de Platón era trocado por las formas alcanzadas de socialización en un estado organizado para su control por parte de las elites. Exponen posiciones teóricas diferentes de esa época entre quienes consideraban al Estado como convención humana que impone una forma de dominación y quienes concebían la sociedad (proceso vital) como comunidad humana basada en leyes de la naturaleza. En ese contexto, esta última perspectiva posibilitaba tomar partido por los oprimidos: "Ya en esa época el concepto de sociedad era un arma en la lucha social", sostienen estos filósofos (Horkheimer y Adorno, 1966, p. 29). Consideran que sucesos históricos como la conformación de estados en imperios y la absolutización del Estado dieron lugar a que los seres humanos olviden el elemento primario de su efectivo proceso vital y a que el sentido común entienda que la conservación de las instituciones dadas en estados e imperio era lo más importante. De este modo, según este análisis, van compenetrándose las ideas de sociedad y dominio.

Basados en análisis de documentación histórica, estos pensa- dores deducen que, tras un largo período en el que las relaciones de dominación se naturalizaron, el concepto de "sociedad" se vuelve a poner en movimiento en la época moderna, al mostrarse con agudeza el enorme contraste entre el estado absolutista y la capa social que de hecho dominaba el proceso vital: la burguesía. Sin embargo, la dialéctica teórico-práctica de apropiación del proceso vital por parte de todos es frenado, según los autores, por teorías no dialécticas que ocultan las contradicciones de ese contexto justificando así la dominación. Tal es el caso de las teorías iusnaturalistas que resuelven el planteo de la fuerza en el estado de naturaleza a favor del derecho en el estado civil transformando el poder del más fuerte en ese contexto de cambio, en el poder legal de la dominación (Horkheimer y Adorno, 1966, p. 31).

En algunos pasajes Horkheimer designó "teorías de la abreviación" a estas teorías de científicos oportunistas que "abrevian" los procesos emancipatorios a través de teorías que detienen el conocimiento de los procesos de liberación contenidos en el tejido del proceso vital. Pero la razón capaz de fundamentar un nuevo orden de cosas basado en la libertad y la igualdad natural de los seres humanos no podía ser la razón proyectada por algunos individuos avaros y posesivos, sino que debía ser la razón de todos y cada uno prosiguiendo el cambio histórico 
hacia la emancipación contenida en la idea contradictoria de "individuo".

Ya en los años treinta Horkheimer había formulado una antropología dialéctica que mostraba que los modelos diversos sobre la naturaleza humana plantean transformaciones estructurales diversas en cada contexto histórico (Horkheimer, 1998). Infirió que el predominio de una mirada pesimista de la naturaleza humana en la primera modernidad deriva de la idea de autoconservación del individuo aislado como medida de todas las cosas que deseaba imponerse (Horkheimer, 1968b).

En el programa de estudios sobre autoridad y familia, Horkheimer retoma esta hipótesis señalando que la construcción del hombre como individuo aislado y egoísta en el período de transición a la modernidad fue una estrategia para el debilitamiento de la formación de los seres humanos en el marco de la autoridad familiar y la socialización enajenada del individuo. Ideas como la de que cada cual es autor de su destino junto a la concepción moral de que el trabajador debe poseer bajos salarios para no entregarse al ocio cuando tenga dinero en su bolsillo fueron claves para la formación de un individuo libre y egoísta. Esta mentalidad dio paso a la explotación de los trabajadores en extensas jornadas que engrandecieron el capital de los empresarios a lo largo del siglo XVIII (Horkheimer, 1968a), marcando un destino de sumisión para quienes experimentaban el acecho del hambre y la miseria y de poder de dominación para quienes poseían los medios de producción y tenían influencia en los poderes del Estado. Se generaba así una conciencia ideológica (conciencia) en los trabajadores, en tanto en esas circunstancias se sintieron libres pero no pudieron derribar las autoridades que se ocultaron tras el poder anónimo de la necesidad económica y del lenguaje de los hechos (Horkheimer, 1968c).

Estos estudios de comienzos de la década de los treinta son asumidos como marco de análisis en el contexto de la segunda guerra mundial dando lugar a un diagnóstico.

\subsection{Estado y comunidad nacional: la guerra de individuos avaros en el capitalismo tardío}

En el ensayo titulado "Estado autoritario" , escrito por Horkheimer entre 1939 y 1940, el análisis de experiencias pasadas alumbran la 
comprensión del contexto de guerra y a la vez el análisis de dicho contexto brinda herramientas para interpretar la historia con nuevos sentidos. En esta obra el autor arriesga hipótesis audaces que enjuician no sólo al sistema nacionalsocialista del cual por su condición de judío debió huir, sino al propio sistema estadounidense que se erigía como modelo libertario para el resto del mundo.

Horkheimer verifica que el mercado estaba transitando hacia un capitalismo monopólico que produce cambios sustanciales a nivel social y a nivel de las funciones del Estado, visibles en la pérdida de libertad de muchos sectores de la burguesía como clase dedicada al comercio. Los organismos de producción y de tráfico comercial son apropiados primero por sociedades anónimas y luego por grandes trusts, dando paso a un capitalismo custodiado por el Estado. El Estado autoritario no es algo exclusivo del nazismo, el cual, en nombre de la nación germana, opera contra la libertad de obreros, comerciantes, productores y contra las diferentes instituciones que los seres humanos crean para organizar sus formas de vivir, sino que es también el de Estados Unidos, donde el autor describe esos mismos fenómenos, aunque construidos desde una administración sutil.

El autor observa que en ese contexto unos pocos individuos -los más poderosos, y los que actúan con mayor perversión- aplican la ley de intercambio no sólo a las materias obtenidas de la naturaleza y las mercancías, sino también a los seres humanos, sometiendo una enorme masa de individuos a arriesgar su vida, en este caso en nombre de la nación. De allí que hinca su sospecha en los estados nacionales estructurados por el propio sistema económico y en la manipulación que éste hace de la libertad de los individuos. Describe la lógica nefasta que deja fuera de juego a la mayoría de los empresarios y liquida la esfera de circulación, la cual pasa a ser dirigida por trust que se financian a sí mismos y por el Estado. Observa un Estado tomado por individuos dispuestos a apropiarse de la totalidad del patrimonio social y cultural, sometiendo violenta $\mathrm{y} / \mathrm{o}$ sutilmente a otros individuos construidos como miembros de una comunidad inventada, estado nacional.

En la construcción moderna del "individuo", el autor ve ahora con mayor claridad una estrategia para la desnaturalización de las relaciones de dominación feudal y el pasaje al capitalismo. Se advierten los intereses de la clase burguesa al promover al individuo como titular de derecho de libertad e igualdad y la fuente de contrariedades en que se constituirían para el género humano de allí en más. Como lo había mostrado Marx, la subversión del orden feudal no podía llevarse a cabo sin la libertad de los siervos 
cuyos brazos laboriosos necesitaba la nueva industria. Pero las condiciones sociales y culturales diferentes de quienes ya ejercían la libertad de comercio y ocupaban los cargos de la administración política y de quienes sólo podían vender su fuerza de trabajo, muy pronto puso al descubierto que el tan mentado nuevo orden moderno era sólo un nuevo orden de desigualdad en el cual debían luchar por la emancipación. Lucha donde si bien los principios modernos de igualdad y libertad habrían de ser las nuevas armas discursivas, se contraponen dos tendencias dialécticas: la de la razón que conceptualiza el proceso objetivado en la historia humana y lo muestra como obra continua y viva del género humano en su conjunto y la de la racionalidad capitalista burguesa que instrumentaliza al hombre y a la naturaleza para mantener el sistema por el cual unos pocos individuos avaros concentran la riqueza y el poder de administrar la sociedad.

En Dialéctica de la Ilustración, Horkheimer y Adorno desenmascaran los fines de la razón moderna burguesa que llevaron a la segunda guerra mundial del siglo. Describen la sutileza de la razón instrumental para implementar una industria cultural donde los medios tienen como fin único que los individuos sirvan a la acumulación privada de la riqueza. Caracterizan la lógica del sistema como dialéctica positiva, que coopta deseos y voluntad de los individuos, cual piezas tan manipulables como la naturaleza, instaurando la representación social de que el proyecto personal de cada ser humano está ligado a la conservación del capitalismo. La indignación ante la injusticia, móvil de la praxis política, es adormecida desde una dominación psicosocial que ya en las primeras décadas del siglo $X X$ trabajaba a nivel del condicionamiento de la conducta a través de la radio, el cine y la propaganda (Horkheimer y Adorno, 1998). La investigación sociológica se constituía en herramienta para la toma de decisiones. La actividad por encargo de agentes de los monopolios económicos conducía al abandono de la fundamentación de la ciencia en el análisis crítico, socavando así la meta de emancipación que puso en movimiento la ilustración.

Es de rigor señalar la claridad con que los frankfurtianos analizaron el modo en que la dialéctica del sistema asumía las contradicciones del proceso vital de la sociedad a través de la administración de los propios individuos y, con gran astucia, domesticaba a éstos originando mentalidades hostiles a todo lo que tienda ir más allá de los límites establecidos por el orden social vigente (Horkheimer, 1968, pp. 96-97). La experiencia de posguerra mostraba el ingreso a una fase donde el capitalismo, de la mano de recomendaciones científico-técnicas, impondría 
las formas de socialización. Los individuos dañados, sólo podrían buscar sus sueños de libertad, igualdad y justicia en los espacios no socializados y en la contingencia. Sólo les cabe avivar los núcleos del buen sentido común que se dispersan como praxis teórica en el tejido social.

\section{La crítica de la modernidad y el sujeto moderno desde América Latina. la perspectiva de Franz Hinkelammert}

En América Latina, desde los años sesenta y setenta, una generación de grandes pensadores, entre los cuales se destacan Franz Hinkelammert y los argentinos Arturo Andrés Roig y Enrique Dussel, ofrecen un análisis del acontecer histórico-social moderno originando una filosofía que si bien no designan como dialéctica crítica, constituye una praxis teórica con un fin emancipatorio que lee el acontecer mundial desde la experiencia de nuestra América. Nos referiremos aquí a los aportes del economista, teólogo y filósofo Franz Hinkelammert, pensador de origen alemán, radicado en Santiago de Chile entre 1963 y 1973, donde vivió una rica experiencia académica y política en el marco de la construcción del movimiento social y político liderado por Salvador Allende. Esa experiencia marcaría para el resto de su vida el compromiso con el pensamiento crítico latinoamericano, patente en el hecho de que tras el golpe de estado chileno, luego de regresar por breve tiempo a Alemania, retornó a estas latitudes en 1976 y se radicó en Costa Rica, país donde permanece hasta la actualidad como director del Grupo de Pensamiento Crítico.

\subsection{La antropología del sujeto material como base de la crítica}

Resulta difícil referir en forma aislada conceptos abordados por el autor como sujeto, mercado, democracia, ética, legalidad, utopías, mitos, entre otros, pues hay entre ellos una profunda articulación. El concepto de sujeto permite referirnos a un entramado de cuestiones problemáticas sobre las cuales el autor dialoga con otros pensadores.
Hinkelammert asume una posición crítica frente a la concepción antropológica moderna ya sea como individuo portador abstracto de derechos naturales o como sujeto de una razón universal instrumental y calculadora y es también crítico de la sociedad y la ética que esa razón prescribe. Recupera la concepción antropológica de Marx, cuya obra ha analizado minuciosamente buscando 
captar el núcleo central que guía sus escritos. Para el autor, ese núcleo es la crítica a la religión, la cual no se encontraría sólo en los escritos juveniles de Marx sino a lo largo de toda su obra y es la fuente principal de su crítica a la economía política.

Así, Hinkelammmert observa que ya en el prólogo de la tesis doctoral de 1841 y en la introducción a la Crítica de la filosofía del derecho de Hegel, de 1844, Marx desarrolla la idea de que son los dioses terrestres mercado, dinero y capital los que subordinan y humillan al hombre. En la obra madura de Marx, la crítica de la religión adopta un nuevo lenguaje que indica como tarea de la economía política la transformación de la sociedad civil burguesa en una sociedad humana o sociedad de la especie humana donde "el ser humano es el ser supremo para el ser humano". El imperativo categórico para esta meta es "echar por tierra todas las relaciones en que el ser humano sea un ser humillado, sojuzgado, abandonado y despreciable" (Hinkelammert, 2013, p. 187). El autor interpreta este imperativo como un "humanismo de la praxis" cuya tarea principal es la transformación de las relaciones de sometimiento en relaciones de una sociedad humana o humanidad socializada donde el ser humano pueda realizarse como tal.

Mientras que en el sistema capitalista la producción se logra soca- vando las dos fuentes originales de toda riqueza, la tierra y el hombre, para el humanismo de la praxis que nuestro autor halla en Marx,el hombre es un ser natural cuya vida depende y es parte del circuito natural y se realiza a través de la relación con otros seres humanos (Hinkelammert, 2010, p. 271). El trabajo es el medio por el cual el sujeto transforma la naturaleza en bienes que satisfacen sus necesidades. El hombre es un ser necesitado diferente al animal en tanto sus necesidades no están naturalmente predeterminadas sino que se especifican en el proceso histórico y se producen con el proceso de producción. La vida propia, la vida de los otros, la vida del planeta y la sobrevivencia de sí mismo es así el primer criterio de toda lógica, de toda racionalidad económica y de las creaciones humanas en general.

Desde el punto de vista del método es posible sostener que estas hipótesis que Hinkelammert va construyendo en su lectura de Marx explicitan una dialéctica de la vida humana que denuncia la inversión en una dialéctica nefasta donde el sistema económico capitalista se cierra en sí mismo oprimiendo al ser humano. En términos adornianos, diríamos que se trata de una dialéctica negativa en tanto niega la totalidad del sistema que coopta todo espacio de autenticidad de los individuos y lo pone al servicio de la autoconservación de sí como individuo administrado, impidiendo la 
realización de la humanidad que le es propia.

La pregunta que nos convocara en el VI Encuentro de Pensamiento Crítico realizado en 2019 en Costa Rica: ¿A qué tiene que responder una sociedad alternativa hoy?, parece ir en la misma dirección que estas hipótesis en cuanto a que desde esta parte del globo el pensamiento crítico ha de aportar a la construcción de una sociedad humana donde el ser humano deje de estar amenazado, sojuzgado y humillado por la lógica de absolutización del mercado. Veamos someramente cómo argumenta el autor la hipótesis de la inversión que se ha producido en la sociedad dañando y sometiendo al ser humano.

\subsection{Utopía como idea reguladora y finitud del sujeto}

El ser humano es un ser vivo finito como los otros vivientes. Pero es atributo propio de él es su tendencia a trascender y pensar en términos universales, a establecer relaciones sociales que van más allá de la relación inmediata, a generar instituciones, mercado, lenguaje, leyes, ciencia y cultura en general. Para ello, el hombre construye utopías, proyecta ideas que orientan su obrar en un contexto histórico concreto. Ahora bien, el carácter finito de la vida humana exige que la racionalidad material sea prioritaria, que el sujeto corporal viviente finito y necesitado sea prioritario. De allí que no es deseable ni saludable que el ser humano se obsesione por las utopías proyectadas y las transforme en metas para cuyo cumplimiento sacrifique la vida de los seres humanos concretos en un presente histórico dado.

Para Hinkelammert, que las utopías dejen de lado las nece- sidades específicas de las personas en su condición de seres finitos y pasen a ser las metas a cumplir a costa de postergar la solución de los problemas de cada presente histórico y la realización plena de todo ser humano es indicador de un sujeto oprimido por sus propias utopías. Tal es lo que ha acontecido con la ley del mercado, transformada en ley absoluta que reduce el ser humano a un individuo calculante que prescinde de toda referencia a los seres humanos concretos como fuente de legitimidad (Hinkelammert y Mora, 2014, pp. 30-32).

En situaciones como éstas las utopías tienen que ser reformuladas teniendo como criterio de verdad la finitud de la vida humana, los ciclos vitales que hacen posible la satisfacción de necesidades y el otro sujeto humano también necesitado. Esta es la tarea del ser humano como sujeto vivo, corporal y necesitado capaz de advertir que las creaciones de 
otros hombres finitos han sido absolutizadas y convertidas en fetiche y que por lo tanto es preciso renovar el sentido de la emancipación y afirmar su materialidad corporal concreta. El ser humano oprimido deviene verdaderamente sujeto cuando toma conciencia de que las objetivaciones son productos de sí mismo, objetos de su propia praxis. Que el objeto es 'subjetivo', porque tiene la dimensión de la praxis (Hinkelammert, 2013, p. 186), expresa el autor en un concepto cercano al de "razón objetiva" de la dialéctica frankfurtiana (Horkheimer, 1968).

En este aspecto de la argumentación es posible explicitar una dialéctica crítica en tanto praxis teórica que denuncia las utopías devenidas fetiches. En algunos pasajes de su obra, Hinkelammert nombra esta praxis como humanismo que el sujeto concreto debe reavivar (Hinkelammert, 2011). Subraya que la propia revolución francesa que proclamó los derechos del hombre y del ciudadano desembocó en una revolución ajustada a los intereses de la burguesía. Los derechos humanos son reducidos a un ser humano abstracto, sobre todo propietario, masculino que explota hasta el extremo a otros seres humanos inclusive mediante el trabajo forzado de la esclavitud. El ciudadano es tal en los límites que establece política y jurídicamente la sociedad burguesa (Hinkelammert, 2013, p. 179). Las revoluciones del período napoleónico constituyen así el termidor de la revolución francesa. La contrarrevolución burguesa absolutiza su propia utopía de emancipación, transformando el modelo de individuo propietario en motor de un modelo de mercado fetichizado.

Sin embargo esos mismos componentes revolucionarios, los derechos humanos y la categoría jurídicopolítica 'ciudadano', desatan "un movimiento de derechos humanos, que va a definir otras luchas futuras de emancipación. El ser humano como ciudadano no es necesariamente burgués, sino que puede volcarse a una emancipación más allá de los límites de la sociedad burguesa dada. Se desarrolla así una historia de profunda conflictividad que el autor grafica en tres grandes asesinatos de quienes lucharon por la emancipación de mujeres, obreros y esclavos: el de Olympe de Gouges, que exigía la ciudadanía de las mujeres, el de Babeuf, que representa el derecho de asociación de los obreros y el de Toussaint Louverture, liberador de los esclavos de Haití (Hinkelammert, 2013, p. 180).

El autor enumera algunos logros exitosos de las luchas por la emancipación, como la introducción de los derechos humanos en las constituciones, en un marco donde los estados de derecho al derecho de propiedad, tienden a excluirlos. Esta intención se agudiza en la actualidad con la estrategia de globalización que vuelve a anular los derechos 
humanos alcanzados en nombre de la totalización de los mercados y de la propiedad privada. Es la crisis del humanismo en la actualidad. (Hinkelammert, 2013, p. 181), caracterizado por la guerra competitiva permanente entre capitales y estados nacionales, por dominar la vida humana y la vida de la naturaleza entera en un grado tal que amenaza la supervivencia del propio planeta. El sujeto humano sojuzgado y abatido "grita" la injusticia que provoca la totalización de la ley del mercado.

Caben aquí preguntas como: ¿Qué sucedió con los valores que orientaron la utopía del hombre moderno? ¿Cuál es la ley, cuáles las normas éticas que conducen a semejante injusticia? Hinkelammert, al confrontar la crítica de la ley efectuada desde la teología con la crítica de la ley de Marx, elabora hipótesis interesantes a las que nos referimos brevemente a continuación.

\subsection{El sujeto oprimido por la ley del mercado y la necesidad de una ética alternativa}

Los análisis de Hinkelammert de algunos relatos fundantes de la tradición judeo cristiana aportan un punto de vista diferente $y$ esclarecedor sobre el concepto de justicia. En varias de sus obras indaga relatos como el asesinato de Caín a su hermano Abel, los diez mandamientos, el pensamiento de Pablo de Tarso y la subversión de su mensaje en el neoplatonismo y Agustín de Hipona.

Para el autor, el pensamiento de Pablo de Tarso está presente en la crítica de la ley realizada por Marx a tal punto que la estructura de esta crítica es idéntica a la de Pablo. El núcleo crítico de este análisis revisa los diez mandamientos, centrándose en los que pueden ser formalizados y por tanto ser expresados en una ética formal. Tres de estos mandamientos -no matarás, no robarás, no mentirás-, forman el núcleo del Código Civil y originan la mayoría de las leyes vigentes en aquél tiempo y en el nuestro. En cambio el décimo mandamiento ("no codiciarás") no puede ser expresado en una norma formal, pues se refiere al sentido de todas las normas (Hinkelammert, 2013, p. 76).

Para fundamentar dos tipos de ética que surgen de los tres primeros mandamientos mencionados y del décimo, el autor recupera las discusiones de Platón con los sofistas y señala:

"A la tesis de que vive mejor aquel que no reconoce ninguna ley, Platón contestó en la politeia, que 
este núcleo de la ley vale siempre e inevitablemente, hasta en el interior de una banda de ladrones. En el interior de la banda de ladrones está prohibido matar, robar y estafar, sencillamente por el hecho que de otra manera la banda de ladrones no puede existir y, consecuentemente, no puede robar tampoco" (Hinkelammert, 2013, p. 76)

En relación con las normas, el autor recupera el fundamento sobre la necesidad de la ley planteado por Kant en La paz perpetua, cuando afirma que ese núcleo de la ley es necesario aún en una supuesta república de demonios.

Sin embargo, para Pablo de Tarso es el décimo mandamiento el más importante. Se trata de una norma que no puede ser meramente formal, porque se refiere al sentido de todas las otras normas y es fundamental para construir un sentido moral de la justicia. La codicia no es instinto o envidia, sino una acción racional con arreglo al fin de obtener la máxima ganancia a costa de explotar al prójimo. La banda de ladrones se sirve del núcleo de la ley y lo pone al servicio de esta codicia. No matarás, no robarás, no mentirás, son normas que se cumplen al interior de la banda, pero se transforman en su contrario frente a los otros. La codicia subvierte la propia ley. (Hinkelammert, 2013, p. 76). La codicia de los bienes del otro es el núcleo de la de la ley del mercado y es así el pecado 'capital', infiere nuestro autor.

Pero ¿qué es la ley del mercado? ¿Cuáles son sus normas de acción? Dos citas analizadas por Hinkelammert en varios de sus escritos son clave para entender este concepto.

La primera es extraída del tomo I de El capital de Marx donde este pensador describe irónicamente "el paraíso de los derechos humanos" dando cuenta cómo el egoísmo propiciado por Jeremy Bentham termina poniendo los derechos de libertad, igualdad y propiedad como intereses por cuidar cada uno lo suyo sin preocuparse de los demás - Las normas no matar, no robar y no mentir que rige en los contratos desatan así un infinito cálculo de utilidad y provecho propio que arrasa con la humanidad y la naturaleza. (Hinkelammert, 2013, pp. 147-148). La ley que echa a rodar el proyecto de Bentham no sería otra cosa que una utopía devenida fetiche, en el sentido expuesto en el apartado 2.2.

La segunda cita que queremos mencionar está tomada de Economía y sociedad de Max Weber, sociólogo alemán conocido por señalar y al mismo tiempo intentar comprender las ambivalencias de la sociedad moderna. Al comentar la frase de Weber, "cuando el mercado se abandona a su propia legalidad no repara más que en la cosa, no en la persona, 
no conoce ninguna obligación de fraternidad ni de piedad" (Hinkelammert, 2013, p. 151), Hinkelammert observa que, cuando Weber habla de legalidad, no se refiere a la llamada ley de oferta y demanda, sino a la ley que rige la propia acción en los mercados. No hablaría, entonces, de lo que estipula el derecho de propiedad y la relación de contrato cuyo núcleo no matar, no robar, no mentir encontramos en el código civil, sino de los intereses específicos de toda acción en los mercados, de una ética del mercado que despersonaliza al ser humano transformando a cada uno en objeto del otro (Hinkelammert, 2013, p. 151).

Es en ese sentido que el cumplimiento de la ley del mercado es el pecado; se trata de una maldad de un rango mucho mayor a los pecados que cometen los deudores cuando incumplen contratos que los llevarían a perder hasta sus medios de vida por pagar sus deudas. Esta lógica actúa en las relaciones internacionales en relación con la deuda que tienen los países con los prestamistas, quienes en nombre de la ley del mercado y la ética del crecimiento llevaron a la miseria a las poblaciones de nuestra América en los años ochenta y a la entrega de los recursos naturales para una extracción que produce daños sin precedentes al medio ambiente y a la vida de la personas (Hinkelammert, 2013, pp. 80-81). Esos prestamistas, -corporaciones financieras globales- cuentan con los tribunales, la policía y los aparatos militares, que son también miembros de la banda a los que acuden para realizar el pillaje de los países deudores. "El laissez faire, laissez passer se transforma en laissez faire, laissez mourir", afirma el autor, en alusión a que la ley que rige para todas las partes contratantes no permite matar, pero la ley de la libertad pura del mercado sí permite dejar morir basados en una ética para la cual los sacrificios humanos son inevitables para asegurar el bien de todos (Hinkelammert, 2013, p. 105)

En síntesis, la ética del mercado es un caso de la "ética de la banda de ladrones". Sus normas se corresponden con los tres mandamientos clásicos: no matar, no robar, no mentir, pero al estar regida por la codicia, el deseo y el interés por todo lo que es de otros, infringe el mandamiento que da el sentido moral de justicia a las normas de acción. Dicho de otro modo, la ética del mercado a través de sus prácticas, de su lógica de acción, reglamenta el mandamiento "codiciarás", estableciendo normas de acción con arreglo a la codicia. Con ello invierte los otros mandamientos e instala una ley que mata, roba y miente para apropiarse de toda fuerza de trabajo, de toda potencialidad humana, de todo recurso natural en cualquier parte del globo. Lo hace reduciendo el ser humano a una nueva forma de homo economicus "con fuerza de ley" 
(Foucault, 2007), ya que cuenta no sólo con el poder de las empresas globales inversoras, hoy parte de las grandes corporaciones financieras, sino con tribunales, aparatos militares y policía.

Pero si el cumplimiento de la ley lleva a someter y aplastar la posibilidad de realización de los seres humanos, debe ser intervenida y abolida. Hemos resaltado el término ley para avanzar en una argumentación que destaca su carácter peculiar que la distingue de lo que entendemos como normativa legal y la posiciona más bien como lógica o racionalidad. Siempre hubo sujetos que resistieron la ley del mercado transformada en ley absoluta. Hinkelammert ha señalado claramente hasta qué punto esa ley distorsiona la vida humana y la naturaleza, ha mostrado la irresponsabilidad de esa ética por los efectos indirectos de su acción directa y ha planteado una ética de responsabilidad por tales efectos, fundamentando así una ética del bien común (Hinkelammert, 2001). Apoyándose en la crítica teológica y en la crítica de la economía política de Marx, sostiene que es el sujeto corporal quien puede y debe derribar la ley que del mercado poniendo en acción e imperativo categórico del humanismo de la praxis al que nos hemos referido en 2.1 .

El pensamiento hinkelammertiano nos abre así preguntas como: ¿de qué manera el sujeto puede derribar la ley del mercado que lo oprime? ¿Qué acciones, qué formas éticas emergen frente a tal utopía absolutizada, convertida en fetiche? Las respuestas precisarían varios análisis de experiencias en distintos lugares del planeta y desde distintas perspectivas. Nuestra intención aquí es esbozar algunas ideas provenientes de los estudios del común.

\section{La perspectiva del común como crítica en la era neoliberal}

Se denomina "estudios del común" a un campo de producción teórica que surge del análisis de luchas sociales y culturales protagonizadas por movimientos que resisten las formas actuales de acumulación del capitalismo neoliberal.

La profundización de la lógica de acumulación a través de la privatización y mercantilización de cada vez más ámbitos de la vida han ocurrido y continúan ocurriendo de manera violenta en numerosas regiones de África y América Latina en el último medio siglo. En nuestra región, esos cambios fueron posibles gracias a un nuevo pacto entre los sectores sociales locales de mayor poder económico y los monopolios transnacionales y necesitó el terror estatal para llevarse a cabo. Las élites económicas en países del cono 
sur como Chile y Argentina venían viendo disminuidas sus ganancias en el marco de las políticas de corte socialista en un caso y de un desarrollismo con visos de estado de bienestar en el otro. Las demandas de los movimientos políticos progresistas aparecían como una amenaza a la lógica de acumulación de riqueza y concentración del poder de administración. Fue así que con el apoyo de altas esferas del gobierno de Estados Unidos esas elites promovieron golpes de estado cuya finalidad fue transformar los estados nacionales en estados neoliberales y ensayar un programa de control total de la sociedad por parte del mercado. (Harvey, 2007). La represión de la protesta social, la desaparición de líderes sociales e intelectuales y el desmantelamiento de las orga- nizaciones populares allanaron territorio y población para la apertura de fronteras a las inversiones directas del extranjero y la libre explotación de los recursos naturales, las privatizaciones de servicios públicos y en general la subsunción de la vida social en su totalidad a las exigencias del capitalismo.

Para resistir a la oleada de expropiación y acaparamiento de bienes naturales (agua, tierras) o de bienes producidos colectivamente (saberes sobre semillas y biodiversidad en general) los movimientos sociales se vieron ante la necesidad de emprender formas de organización de democrática directa para una resistencia 'común' adecuada a la situación específica.

\subsection{Lo común como política frente a la expropiación neoliberal}

Economistas, filósofos, juristas y politólogos de distintas latitudes han analizado estos movimientos poniendo la mira en que lo común emerge en ellos como principio efectivo de lucha en el marco de una gubernamentalidad neoliberal que además de los procesos violentos aludidos adopta estrategias blandas de construcción de la subjetividad para formar y apropiarse de distintas formas del común o de los comunes. Al respecto, Hardt y Negri señalan que los economistas neoliberales intentan expulsar lo común de las relaciones económicas, pero a la vez se lanzan a conquistarlo en su pretensión de que nada quede fuera del mercado y ningún bien quede sin propietarios. Para ello construyen un sentido común según el cual el lugar de la libertad y la innovación se sitúa en lo privado y ajustan el concepto de "común" al de libre uso, libre expresión, libre interacción y riqueza social. ((Hardt y Negri, 2011, pp. 86- 287).

En América Latina los estudiosos del común advierten sobre el peligro de que los "comunes" queden cooptados por el capital para proveer 
formas de reproducción de bajo costo. Caffentzis y Federici (2013) hacen notar que, en el marco de estos procesos, el Banco Mundial en 2012 dictaminó que toda investigación que llevase su sello debía ser de libre acceso mediante una licencia Creative Commons, organización sin fines de lucro que favorece mayor acceso a la información en Internet. Pero tras esa imagen protectora de los bienes comunes mundiales es esa misma banca internacional la que estuvo y está detrás de la expulsión de pueblos de las selvas y los bosques donde han vivido durante generaciones para la creación de parques temáticos u otro tipo de atracciones comerciales que restringen el acceso a quienes puedan pagar. Junto con la ONU, esa entidad ha reafirmado su derecho de gestionar los principales ecosistemas del planeta para abrirlos a la explotación comercial en nombre de preservar la herencia común de la humanidad (Caffentzis y Federici, 2013, pp. 58-61).

Por su parte, Zibechi (2012) pone el acento en que los bienes comunes no son dados ni son esencialmente objetos materiales, sino relaciones y prácticas sociales producidas por los seres humanos con la finalidad de garantizar la reproducción de la vida. El autor hace notar que gran parte de los bienes comunes producidos han sido gestionados por los estados recibiendo entonces la denominación de bienes públicos, y señalan la importancia de hacer esta distinción en el marco de una lógica neoliberal donde los estados ceden lo público a grupos empresarios. En tal sentido, invita a conectar la lucha por lo público con la construcción de lo común en una suerte de reapropiación de lo público en tanto común frente al riesgo de que sea privatizado y convertido en producto del mercado (Zibechi, 2012, pp. 49-84)

En nuestra América, estos procesos implican una lucha desigual a causa del rol del estado que luego de años de gobiernos de facto pasó a ser legitimado a través de democracias vaciadas y manipuladas por un pensamiento neoliberal que vía medios de comunicación construye un sentido común basado en valores de libertad y dignidad individual (Harvey, 2007, p. 16). En ese sentido es valiosa y oportuna la discusión ideológica y teórica acerca de que si bien lo común está asociado a comunidades locales que trabajan y cuidan un determinado común, no están exentas de conflictividad y desigualdad en el poder para la toma de decisiones. La historia de los comunes muestra comunidades con relaciones no igualitarias donde el patriarcado o los privilegios ancestrales de clanes producen división llevando incluso a que algunos miembros de la comunidad colaboren con los procesos de cercamiento del capitalismo (Zibechi, pp. 65-96). Al respecto, el autor destaca que el tipo de participación asociada a los comunes es el hacer comuni- 
tario en tanto prácticas y trabajos colectivos que sustentan lo común, un hacer político y de organización social que se distingue del hacer del mercado y el estado.

\subsection{La 'formación' del común para su mercantilización en el neoliberalismo}

\begin{abstract}
El capitalismo neoliberal en las últimas décadas tiene la formación o configuración de los comunes como estrategia de acumulación. Además de la acumulación por desposesión que reedita las formas de acumulación originaria del capitalismo entre los siglos XII y XVIII $\mathrm{y}$ el posterior cercamiento de las últimas propiedades comunitarias inglesas en el siglo XIX descriptas claramente por Marx; además de la expropiación de los comunes producidos como riqueza social por las comunidades, el neoliberalismo utiliza la estrategia de configuración de lo común. En esta línea, Hardt y Negri denuncian que el capitalismo actual para obtener renta a través de sus inversiones crea las condiciones para un despliegue sin precedentes de cooperación social autoorganizada para seguidamente capturarla y expropiar la riqueza común producida y alojada en los saberes, las prácticas efectivas, los códigos, las imágenes entre otros (Hardt y Negri, 2011, pp. 155-158).
\end{abstract}

Estas estrategias neoliberales se apoyan en la teoría del capital humano elaboradas por economistas norteamericanos como Schulz, Gary Becker y Friedman que construyeron un modelo de hombre "empresario de sí mismo" claramente tematizado por Foucault (2007). El filósofo francés observa que estos economistas producen un discurso que desactiva el potencial contestatario del marxismo según el cual el trabajador vende su fuerza de trabajo a cambio de salario y lo describe como capital que produce una renta y busca maximizar sus ganancias invirtiendo en su propia formación. Esta construcción de subjetividad tiene como correlato objetivo la gestión de recursos humanos por parte de las empresas que envían señales a los individuos en forma de incentivos a su búsqueda de maximización de su rendimiento. Se produce una competencia transversal donde las grandes empresas promueven la cooperación entre los asalariados y la colaboración de los consumidores y usuarios como estrategia para producir en forma constante comunes que quedan de este modo subsumidos a la lógica del capital y son apropiados gratuitamente por empresas de todo tipo y por instancias de la administración pública. A través del management se promueve la identificación de los objetivos profesionales y vitales de los trabajadores con los de las empresas, mientras que el marketing 
"busca identificar (por ejemplo a través del big data) y construir comunidades y saberes de usuarios en torno a formas de pensar, imaginar, desear y de todo aquello que puede capturar la atención de los públicos" (Saidel, 2016:12).

En este marco donde el neoliberalismo forma comunes para apropiárselos como ganancia empresarial a través de engañosas estrategias de subjetivación que manipulan los valores de libertad y dignidad que los grandes grupos financieros hacen discurrir como prácticas empresari- ales cabe preguntarnos: ¿por qué lo común tiene que ser producido para ser expropiado por empresas cada vez más concentradoras de la riqueza producida? ¿De qué manera podemos desidentificarnos de semejante fuerza configuradora? Las preguntas tienen menos respuestas a la mano que las que mostraron las comunidades que vieron cercados sus territorios y expropiados bienes como el agua y los recursos naturales a los que tenían acceso. Sin embargo, las experiencias de enajenación que sobrevienen a pesar de las ilusiones que crean las estrategias empresariales, alientan expectativas.

\subsection{La política instituyente del común como alternativa}

El filósofo Pierre Dardot y el sociólogo Christian Laval, en la obra escrita por ambos en 2015, Común. Ensayo sobre la revolución en el siglo XXI, analizan las experiencias de resistencia al avance neoliberal sobre los comunes en distintos puntos del planeta. A partir del diagnóstico foucaultiano sobre la gubernamentalidad neoliberal subrayan que es la ayuda del estado la que ha hecho posible que el capital se dirija de un modo cada vez más imperativo y rápido a la transformación de las relaciones sociales y las subjetividades para la acumulación y ha abierto paso a que el neoliberalismo ponga sus ojos y sus manos en lo común. Para los autores, esto rompe las esperanzas de que el Estado vuelva a encastrar la economía capitalista en el derecho republicano y la justicia social e incluso en la democracia liberal (Dardot y Laval, 2015, p. 17).

De allí que pongan en valor la acción de los movimientos sociales cuyo hacer es una lucha orientada a la reapropiación colectiva y democrática de espacios acaparados por oligopolios privados y gobiernos. En estos hechos distinguen dos sentidos de lo común: el de los bienes que son expropiados y la organización política. De un lado, la violencia del neoliberalismo para apropiarse de bienes comunes y del otro, la capacidad de organización de poblaciones y de organizaciones económicas, lideradas en muchos casos por mujeres que resisten de manera organizada esta ola de violencia y destrucción. 
Frente a la estrategia neoliberal de formación de lo común se plantean las cuestiones a nuestro entender más delicadas a nivel del análisis y la conceptualización y por cierto también a nivel de la acción política. Tenemos por un lado que el capitalismo neoliberal muestra un nivel de competencia global donde ya no le basta sólo "las prácticas extractivas y de privatización y mercantilización de los bienes comunes naturales" sino que avanza al cercamiento de otros comunes como los informacionales y la cooperación y colaboración entre los trabajadores de las empresas. (Saidel, 2016). Por otro lado, tenemos a los trabajadores colaborando, cooperando y produciendo nuevos comunes de conocimientos, de prácticas, de creatividad y de interacción. Pero, ¿para quién? ¿Por qué las corporaciones empresarias y financieras globales han de llevarse el tiempo propio y la satisfacción que produce el hacer con otros?

Preguntas de este tipo son homólogas a las que laten en las luchas de las poblaciones campesinas frente a los cercamientos de tierras y expropiación de bienes naturales. En este caso, en entornos más bien urbanos, la expropiación del tiempo propio y la construcción de subjetividades deseosas de consumir los productos que el mercado produce a través de esa lógica invita a desidentificarse de éstas y construir un ethos político que permita reapropiarnos de lo que continuamente es expropiado. Al respecto, concordamos con Saidel cuando afirma que, en el marco del fomento y redescubrimiento de los comunes por parte de las políticas neoliberales, se destaca el papel de las luchas en torno a lo común:

(...) como el momento de expresión de un antagonismo inmanente a la sociedad neoliberal entre las lógicas de una configuración de lo común en términos capitalistas, y las luchas que defienden y producen lo común, a partir de las cuales se forja la posibilidad de generar otras formas de habitar que ya no estén subsumidas a la lógica de la competencia y a la explotación de la cooperación social. (Saidel, 2016, p. 16)

En esa dirección, pensamos que una subjetivación diferente implica un trabajo sostenido sobre nosotros mismos en tanto seres humanos asediados en forma constante por mecanismos de cooptación de lo que hacemos individual y conjuntamente para habitar nuestras ciudades, nuestros entorno natural y nuestro mundo. Implica una acción que instituya comunes a través de la gestión de diferentes comunes para su preservación. En este sentido es oportuno el concepto de política que Dardot y Laval recuperan, desde Castoriadis, para quien "la política es la actividad instituyente que realiza la sociedad instituida" y con la idea que en la democracia del común prima el poder de lo insti- 
tuyente porque le toca crear nuevas formas y reglas institucionales para reorganizar lo social de modo que

\section{Reflexiones finales}

A lo largo de este trabajo hemos desarrollado un marco referencial que articula aportes de la tradición histórica crítica de los últimos setenta años que entendemos fundamentales para la construcción de un hacer político, científico y pedagógico alternativo a la racionalidad que hoy se alza como pensamiento y destino único mientras avanza destruyendo la vida humana y la naturaleza.

En el primer apartado presentamos la lectura del marxismo realizada en el contexto de las guerras mundiales del siglo XX por algunos pensadores de la Escuela de Frankfurt. Mostramos que el diagnóstico de ese presente de guerra por el reparto del mundo entre grupos económicos que medran en el poder del Estado los conduce a un análisis histórico-crítico de los orígenes de modernidad y a señalar espacios de búsqueda en medio de un horizonte que ven sombrío. En ese sentido su argumentación dialéctica sobre el contenido de los conceptos individuo y sociedad constituye un arma crítica frente a lo que la burguesía erige como verdad única.

Así en el término "individuo" vieron una categoría portadora de la propiedad no avance sobre el derecho al uso de lo común.

los principios de libertad e igualdad que legitiman la "modernidad" como era en permanente cambio. Más allá de que la experiencia históricosocial, muestra el contenido conceptual marcado por la clase burguesa (individuo propietario, igualdad ante la ley, racionalidad instrumental), el "individuo" es portador de los principios emancipatorios y de las tensiones y contradicciones sociales alojadas en ese modelo de hombre . Aún quienes fueron menoscabados por la violencia de las armas al ser desarraigados de sus territorios y comunidades, aún quienes padecen la violencia del disciplinamiento en las instituciones burguesas, han de emprender luchas políticas recurriendo a los valores de libertad e igualdad que legitiman la sociedad moderna en el marco del dinamismo y renovación continua que le imprimió esa racionalidad.

Por su parte entendimos que argumentan en torno al término "sociedad" porque valoran su alcance global como marco donde actúa y se proyecta el individuo moderno. Desde ese lugar desnaturalizan su homologación a la sociedad altamente industrializada de la burguesía, mostrando a ésta como "momento" histórico de la sociedad 
entendida como proceso humano vital. Vimos también que su crítica a la "comunidad" (Gemeinschaft) del nazismo la hacen extensiva al estado nacional moderno en tanto comunidad nacional construida al servicio de la monopolización del mercado por parte del capitalismo. En ese sentido, denunciaron la alianza de los estados soberanos con la clase burguesa como generadora de un estado autoritario que no podría generar procesos de emancipación. En definitiva denuncian una dialéctica falsa del sistema al intentar cooptar todos los espacios de libertad de los individuos, proponiendo una dialéctica negativa en tanto las alternativas han de buscarse en ámbitos no socializados y contingentes.

En el segundo apartado consignamos los aportes de la perspectiva de. Hinkelammert quien, al analizar los acontecimientos de la modernidad desde América Latina, desmonta los eslabones de su lógica destructiva y recupera los aportes de la tradición crítica que posibilitan una alternativa edificante. Destacamos la recuperación que Hinkelammert realiza de la antropología presente en el pensamiento joven y de la madurez de Marx según el cual "el ser humano es el ser supremo para el ser humano", supuesto que deriva en el imperativo categórico de "echar por tierra todas las relaciones en que el ser humano sea un ser humillado, sojuzgado, abandonado y despreciable". Hicimos hincapié en el humanismo de la praxis que propone el autor a partir de su análisis de las utopías y de su indicación de que éstas deben ser ideas reguladoras que orienten las acciones pero no deben absolutizarse, ni transformarse en fetiches o fines que pongan como medio la vida de los sujetos concretos, teniendo en cuenta que el hombre es un ser finito y necesitado de los otros hombres y de su entorno natural.

En tal sentido interpretamos que las hipótesis que el autor va construyendo a partir de su estudio atento de la obra de Marx explicitan una dialéctica material de la vida humana que denuncia la inversión realizada por el sistema económico capitalista al cerrarse en una dialéctica nefasta que oprime al ser humano. Vimos así una correspondencia entre estos análisis y la crítica frankfurtiana a la dialéctica del sistema moderno por cooptar los espacios de autenticidad de los individuos y proponer una dialéctica negativa como vía de afirmación del individuo dañado, según lo designa la teoría frankfurtiana o el sujeto oprimido y humillado por lasa utopías de otros sujetos también oprimidos, en el lenguaje hinkelammertiano.

Nos detuvimos a considerar la utopía del mercado como construcción opresora del sujeto material, para lo cual analizamos pasajes de 
la obra del autor donde distingue legalidad y ley. La vinculación de la concepción de ley de Pablo de Tarso con una lectura crítica de Marx y Weber lo llevan a la sugerente distinción entre la legalidad del mercado llamada ley de oferta y demanda y la ley que rige la propia acción en los mercados. De este modo observa que la ley del mercado constituye una versión de la ética de la banda de ladrones pues, a través de sus prácticas, de su lógica de acción, invierte el mandamiento "no codiciarás" y establece normas de acción con arreglo a la codicia. Con ello invierte los otros mandamientos e instala una ley que mata, roba y miente para apropiarse de toda fuerza de trabajo, de toda potencialidad humana, y de la naturaleza en todo lugar del globo. Hallamos una similitud entre el sentido dado aquí al término ley y la expresión de Foucault "fuerza de ley" para aludir a la ley del mercado en el neoliberalismo que, por encima de cualquier ley escrita actúa reduciendo a los seres humanos a capital humano que deben formarse a sí mismos, invertir en sí mismo como empresarios de sí.

La propuesta hinkelammertiana según la cual el sujeto corporal quien puede y debe derribar la ley que del mercado a través de una ética del bien común y de la responsabilidad nos llevó a articular las perspectivas con los estudios del común.
Así, en el último apartado expusimos aportes de los estudios del común donde este término presenta una referencia objetiva a los bienes comunes o comunes naturales 0 artificiales y también una referencia a los comunes como principio de acción política siempre puntual y ajustado al común que se halla amenazado por la lógica de acumulación del capital.

Al referirnos a estos estudios quisimos integrar a la línea históricocrítica un conjunto de aportes de las últimas décadas claramente situados en el diagnóstico del capitalismo neoliberal que intentan dar cuenta de cómo aquella lógica del capitalismo que Marx describe claramente en el capítulo XXIV del tomo I de $E l$ Capital (cercamiento, desposesión, expropiación) se repiten con crudeza en la fase neoliberal.

Intentamos aclarar la relevancia que tiene el hecho de que en el neoliberalismo no sólo expropia comunes y bienes comunes existentes, sino que las nuevas formas de acumulación originaria se presentan como formación o configuración del común. Las empresas utilizan estrategias para que los objetivos de los trabajadores se identifiquen con los de las empresas, y estrategias de marketing para construir comunidades de usuarios que colaboren en la producción de comunes que traen nuevos beneficios a las empresas. 
En este punto de avance de la lógica neoliberal a todos los rincones de la vida humana, los individuos dañados pueden encontrar en su producción de comunes una estrategia de resistencia en una lucha que en la mayoría de los casos es de una violencia sorda, ensordecida o más bien ocultada por los medios masivos y por la cultura de espectacularización de los medios masivos de comunicación. El sujeto grita la opresión asesina de la ley del mercado y despierta en medio de la destrucción que crece por doquier. Hinkelammert en cada uno de sus escritos ha tomado alguna de las acciones de robo, de mentira y muerte como casos de la ética imperante. Los estudiosos del común apenas alcanzan a compendiar las luchas desiguales que deben librar por los comunes que constantemente son apropiados por el neoliberalismo.

No quisiéramos concluir este trabajo sin señalar que aunque difícil por desigual que es en este momento esa lucha, su valor radica precisamente en que se da esa lucha, hay vida en disputa, hay comunes, hay sujetos concretos con valentía para hacer frente a semejante avaricia y atropello de un sistema abstracto cuyas debilidades también se hacen patentes al tener que dar esa lucha.

\section{Referencias bibliográficas}

- Caffentzis, G. y Federici, S. (2013). Comunes contra y más allá del capitalismo. El Apantle. Revista de Estudios Comunitarios (1). Recuperado de: https://horizontescomunitarios.wordpress.com/2017/01/16/apantle1/

- Dardot, P. y Laval C. (2015). Común. Ensayo sobre la revolución en el siglo XXI. Barcelona: Gedisa.

- Deleuze, G. (2005). “Posdata sobre las sociedades de control”. En Ferrer, C. (comp.) El lenguaje libertario. La Plata: Terramar.

- Foucault, M. (2007). Nacimiento de la biopolítica. Curso en el Collège de France (1978-1979). Buenos Aires,Argentina: Fondo de Cultura Económica.

- Hardt, M. y Negri, A. (2011) Commonwealth. El proyecto de una revolución del común. Madrid: Akal.

- Harvey, D. (2007). Breve historia del neoliberalismo. Madrid: Akal.

- Hinkelammert, F. (2002). El retorno del sujeto reprimido. Bogotá: Universidad Nacional de Colombia.

- ------ (1998). El grito del Sujeto. Disponible en: http://www. pensamientocritico.info/index.php/libros/libros-de-franz-hinkelammert/ 
- --------- (2013). La maldición que pesa sobre la ley. Las raíces del pensamiento crítico en Pablo de Tarso, Ed. Arlequín. Digitalizado por Biblioteca "P. Florentino Idoate, S.J. Universidad Centroamericana "José Simeón Cañas"

- $\quad$------ (2015). Solidaridad o suicidio colectivo, San José: Ambientico. Disponible en: http://www.zbw.eu/econis-archiv/bitstream/handle/

- Hinkelammert, F. y Mora, H. (2014). Economía, vida humana, bien común. Disponible en: http://coleccion.uca.edu.sv/franz-hinkelammert/items/ show/2370

- Horkheimer, M. (1968a). Autoridad y familia. En Horkheimer, M. (1998) Teoría crítica. Buenos Aires: Amorrortu, pp. 76-150.

- -------- (1968b) Egoísmo y movimiento liberador. En Horkheimer, M. (1998) Teoría crítica. Buenos Aires: Amorrortu, pp. 151- 222.

- -------- (1968c). Observaciones sobre antropología filosófica. En Horkheimer, M. (1998) Teoría crítica. Buenos Aires: Amorrortu, pp. 50-76.

- $\quad$-------- (1973). Crítica de la razón instrumental. Buenos Aires: Sur.

- ------- (1986). “El estado autoritario". En: Horkheimer, M. Sociedad en transición: estudios de filosofía social. Barcelona: Planeta-Agostini.

- -------- (1998). Observaciones sobre antropología filosófica. En: Horkheimer, M. Teoría crítica. Buenos Aires: Amorrortu, pp. 50-75.

- Marx, K. (2001). El capital. Tomo L. México: FCE,

- Saidel, M. (2016). Los comunes en el contexto neoliberal: entre desposesión, expropiación y configuración. En: Actas de las I Jornadas Nacionales de investigación en Ciencias Sociales de la Universidad Nacional de Cuyo, Mendoza. 25-26 de agosto de 2016. Disponible en: https:// bdigital.uncu.edu.ar/10066

- Zibechi, R. (2012). Los trabajos colectivos como bienes materiales/ simbólicos. El Apantle. Revista de Estudios Comunitarios (1), pp. 77-98.

- https://horizontescomunitarios.wordpress.com/2017/01/16/apantle1

\section{Notas}

1. El presente escrito sólo toma algunos conceptos del primer apartado del trabajo leído en el mencionado evento, pero en una argumentación totalmente reestructurada. 
de Investigación y Posgrado de la Universidad Nacional de Cuyo para el período 2019-2021.

3. Esta obra recoge unas conferencias que los autores prepararon para Radio Asia entre 1963 y 1964 y que fueron repetidas en francés en el programa de la Universidad Radiofónica Internacional, bajo la dirección de la radiodifusión francesa.

4. Este ensayo se publica en 1942 en el volumen Walter Benjamin zum Gedächnis (Homenaje a Walter Benjamin) junto con Vernunft und Selbsterhaltung ("Razón y autoconservación") y con las Tesis sobre la historia de Benjamin. A pesar de tratarse de una publicación en homenaje a su fallecido amigo, la versión es policopiada y, en ese sentido, marginal.

5. No podemos dejar de señalar la capacidad de anticipación del autor en estos análisis. Hoy ocupan un lugar preeminente los análisis de Foucault sobre el origen del neoliberalismo y el rol de la teoría del capital humano sobre la construcción de subjetividades como "empresarios de sí". Sin embargo no es frecuente la alusión a esta hipótesis temprana de Horkheimer que refiere la alianza entre estados y monopolios para lo que llama manipulación o administración del individuo.

6. Arturo Andrés Roig ubica su producción en el campo de la historia de las ideas latinoamericanas, mientras que Enrique Dussel ha designado su método como analéctica, por entender que interpela a la filosofía europea desde la alteridad de nuestra América. Para quienes nos hemos formado con ellos en su Mendoza natal a mediados de los setenta, y luego hemos ido siguiendo su recorrido académico a partir del obligado exilio de ambos en la dictadura cívico-militar. Estos filósofos, junto a Franz Hinkelammert, forman parte de una misma comunidad filosófica cuyo núcleo firme es la afirmación del sujeto material histórico de nuestra América como sujeto de una filosofía de alcance explicativo y comprensivo universal.

7. Extractamos parte de la cita comentada: "La órbita de la circulación o del cambio de mercancías, dentro de cuyas fronteras se desarrolla la compra y la venta de la fuerza de trabajo, era, en realidad, el verdadero paraíso de los derechos del hombre. Dentro de estos linderos, solo reinan la libertad, la igualdad, la propiedad y Bentham. La libertad, pues el comprador y el vendedor de una mercancía, v. gr. de la fuerza de trabajo, no obedecen a más ley que la de su libre voluntad. Contratan como hombres libres e iguales ante la ley. El contrato es el resultado final en que sus voluntades cobran una expresión jurídica común. La igualdad, pues compradores y vendedores sólo contratan como poseedores de mercancías, cambiando equivalente por equivalente. La propiedad, pues cada cual dispone y solamente puede disponer de lo que es suyo. Y Bentham, pues a cuantos intervienen en estos actos solo los mueve su interés". (Marx, 2001, p. 128. Citado en Hinkelammert, 2013, pp. 146-147)

8. No podemos aquí explayarnos sobre el concepto de sacrificialidad como racionalidad del mercado, que tan lúcidamente ha argumentado el autor en varias de sus obras.

9. Creemos que discursos que denuncian la disolución del individuo moderno en "dividuos" o fragmentos "dividuales" de su integridad como individuo, (Deleuze, 1990), de algún modo apelan a saldar las deudas con los principios libertarios que definen al individuo al denunciar las contradicciones flagrantes del sistema. 